\title{
OS ASPECTOS DA POLÍTICA RETRIBUTIVA NA SOCIEDADE PRIMITIVA PARA O DESENVOLVIMENTO DO DIREITO.
}

\author{
Frederico Marcos Krüger*
}

\section{RESUMO}

O presente trabalho irá proporcionar um entendimento sobre o desenvolvimento do comportamento das relações obrigacionais, focado na gênese das sociedades primitivas delineada no comportamento do homem primitivo na sobrevivência e na manutenção no grupo gentílico, e que para tanto os seus reflexos comportamentais desta sobrevivência em grupo. Nesse sentido, a ciência jurídica, será eminentemente a ferramenta essencial para um discernimento profundo do desenvolvimento deste trabalho, demonstrando o homem jurídico antropológico, o seu comportamento nas relações obrigacionais, consigo, com o seu grupo e com outras comunidades gentílicas, fortalecendo o sistema da política retributiva.

Palavras Chaves: Ciência, Direito, sociedade, obrigações, retribuição.

\section{THE POLITICIAN RETRIBUTIVE ASPECTS IN THE PRIMITIVE SOCIETY FOR THE DEVELOPMENT OF LAW.}

\begin{abstract}
The present work will provide a knowledge about the development of the behavior of obligatory relationships, focused on the genesis of primitive societies outlined in the behavior of primitive man in survival and maintenance in the gentile group, and that for this purpose their behavioral reflexes of this group survival,. In this sense, legal science will be eminently the essential instrument for a profound discernment for the development of this work, demonstrating the anthropological juridical man, his behavior in obligatory relations, with himself, with his group and with other gentile communities, strengthening the system of retributive politic.
\end{abstract}

Keywords: Science, law, society, obligations, retribution.

\section{INTRODUÇÃO}

Para compreender os fatos contemporâneos e prever novos acontecimentos sociais e jurídicos, e rever as novas interpretações, e os seus valores que surgem na temporalidade da

\footnotetext{
* Bacharel e Mestre em Direito pela UNICESUMAR; Doutor em Direito pela Faculdade Autônoma de DireitoFADISP; Pós Doutor em Direito em Constituzione e Diritto Civile negli ordinamenti Europeo e Latono Americano pela Università di Messina-Itália; Pós Doutorando em Ciência Jurídicas pela Universidade Vale do ItajaiUNIVALI.
} 
sociedade, é necessário compreender os atos e fatos e os seus eminentes valores ocorridos nas datas que o ensejaram.

É nesse viés, que essa relação jurídica hermenêutica irá se estender aonde, o palco das gêneses humanitárias vem se desenvolvimento e perpetuando, cativando a sua cultura, interpretando e criando novos elementos jurídicos costumeiros para o equilíbrio da sociedade. Uma vez que o homem saiu do Estado de Natureza e passou a integrar o Estado Moderno ou solidário. E é nessa condição hermenêutica moderna, a cultura vem adquirindo novas formas de amplíssimo comportamento, mas jamais se deve lançar mão das verdadeiras características na formação jurídica e social do povo, daqueles que um dia fez menção na honradez em transmitir para o seu povo.

\section{1) As características do desenvolvimento e a endoculturação do comportamento.}

Por sua natureza, o homem primitivo, se comportava como tal as experiências dos fenômenos naturais e nas relações com outros e aos demais personagens na mesma etnia.

Que estava inserido, no melhor da linguagem, ele agia conforme o seu habitat como um todo, pois ele sobrevivia em grupo, e a sua sobrevivência dependia dos outros membros e assim, proporcionando a política da reciprocidade retributiva.

Uma manifestação lícita de sobrevivência através das regras internas para a sua manutenção de vida, pois todos dependiam de todos para a perpetuação de sua espécie.

E nas relações obrigatórias, fundamentadas pelas atividades econômicas, e desta proporciona o desenvolvimento social, emergindo uma superestrutura de uma "sociedade", pois bem como retrata Carlos Campos, "a solidariedade não é mais do que a coesão em torno de certos interesses essenciais e que se manifesto no sentimento de socialidade ", é nesse sentimento de solidariedade a essencialidade o cunho objeto está na socialidade do homem primitivo, pois existia um sentimento essencial político de coletividade.

E qual seria o conceito, de sociedade? Uma vez que o homem primitivo possuía o sentimento de solidariedade com o seu grupo, uma regra típica interna, dos usos e dos costumes, viver em sociedade, era e é a mais valia, pois bem relata Telles Junior:

\footnotetext{
${ }^{1}$ CAMPOS, Carlos. Sociologia e Filosofia do Direito. Belo Horizonte, Ed. Cardal, $2^{\text {a }}$ Ed. Belo Horizonte, 1961, p. 39.
} 
Na sociedade, não há senão indivíduos. Mas estes indivíduos estão associados, e tal associação é a causa dos fenômenos novos que caracterizam a vida social. A sociedade não é uma soma de indivíduos. Ela resulta de consciências "associadas, combinadas, e combinadas de uma certa maneira; é dessa combinação que resulta a vida social e, por conseguinte, é essa combinação que a explica",.

Preliminarmente, para compreender e alcançar algumas, das inúmeras informações, a respeito do tema que está sendo abordado, transcrevemos nas palavras de Ralph Linton, sobre esse primeiro momento de sociedade, que "sociedade é todo grupo de pessoas que vivem e trabalham juntas durante um período de tempo suficiente longo para se organizarem e para se considerarem como formando uma unidade social, com limites bem definidos ${ }^{3}$ ".

Assim, a reciprocidade retributiva era (ou é) uma manifestação legal.

Se interpreta como um exercício de uma atividade, voltada através das regras e de normas fecundadas na gênese e no desenvolvimento das sociedades primevas, pois os seus membros se comportavam na mesma sintonia e nas mesmas manifestações comportamentais dentro de uma rígida sistemática retributiva.

Esse instinto, a princípio se observa ter uma característica um tanto naturalística em que o homem exercitava, e acreditava ele, ser de uma ordem de seu próprio instinto, um "animal racional".

Este, pois possuía uma racionabilidade natural, uma atitude cognitiva e distintiva dos demais

Mas, considerava adequado e o de que era inadequado no momento, ou, em termos o que era necessário para a sua sobrevivência, um consenso de justiça consigo mesmo e para os demais que o acompanhava.

É possível observar nas palavras de Giorgio Del Vecchio, que acredito, se encaixa muito bem como sendo um Direito Natural, "Direito Natural e, pois, o nome que se designa, por tradição muito antiga, o critério absoluto do justo ${ }^{4}$, para o homem primitivo era um comportamento diário.

Nestes atos valorados e naturais, o homem deriva dos seus comportamentos oriundos da própria natureza que o circundava, ou da sua própria natureza neural humana e por sua vez,

2 TELLES JUNIOR, Goffredo. A Criação do Direito, $3^{\text {a }}$ ed. São Paulo: Saraiva, 2014, p. 266.

${ }^{3}$ LINTON, Ralph. O homem: uma introdução à antropologia. Trad. Lavínea Vilela. 12a Ed. São Paulo, Ed. Martins Fontes, 2000, p. 97.

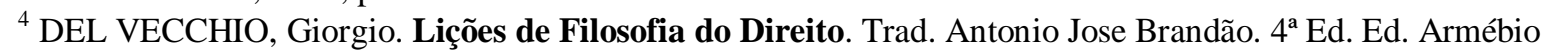
Amado, Coimbra, 1972, p. 47. 
se portava como uma pessoa, um indivíduo em que se empenhava na evolução, bem explica em Digesto de Justiniano:

O direito das gentes é aquele do qual os povos humanos se utilizam. O que permite facilmente entender que ele se distancia do natural, porque este é comum a todos os animais e aquele é comum somente aos homens entre $\mathrm{si}^{5}$.

Se esse Direito era justo (conforme era disciplinado pelo grupo social) e natural de forma empírica no seu comportamento, o homem se valia desses sentidos, de se permanecer em grupo, para a sua própria sobrevivência, bem entendido como comunidades "gentílicas".

A questão é "o que conduzia esse homem racional a se comportar em grupo?” A resposta pode estar exatamente em uma qualificadora denominada de laços de sangue, um comprometimento muito comum naqueles tempos, em que Wilson de Souza Campos Batalha, transcreve:

Ensina D'Aguanno (ob. Cit., p. 536) que, inicialmente, quando os grupos humanos começaram a ser estáveis, o grupo inteiro possuía coletivamente a propriedade e agia como um todo, dada a solidariedade entre os membros que compunham e o fato de que todos se consideravam unidos pelos vínculos de sangue ${ }^{6}$.

$\mathrm{Na}$ época os laços de sanguíneos possuíam um valor inestimável e de uma pura honradez diante de todo o grupo primitivo, pois o indivíduo é exposto pela própria honra, e que com isso, na época vinculava com as obrigações impondo para isso a própria vida, como forma tradicional de garantia, um contrato verbal com a sua família tribal, no comprometimento de suas obrigações.

Ainda o mesmo autor, Campos Batalha, entende que " $A$ origem do contrato encontra-se manifestamente nos hábitos de ajuda recíproca benévola que nasceram nos povos primitivos", a essa benevolência está na reciprocidade que aos poucos foram ganhando os traços da moralidade.

Esse instrumento de contrair obrigações, conforme disposto, é uma ferramenta que adveio com o surgimento e as relações de Estado, uma modalidade também de toga antiga, aonde segundo Del Vecchio traduz com sabedoria, "É notório ter a teoria que põe no

\footnotetext{
${ }^{5}$ DIGESTO de Justiniano, líber primus: Introdução ao Direito Romano, Trad. Hélcio Maciel França Madeira. $4^{a}$ Ed. Ver. Da trad. São Paulo: Ed Revista dos Tribunais, 2009, p. 20.

${ }^{6}$ BATALHA, Wilson de Souza Campos. Introdução ao Estudo do Direito. Ed. Forense, Rio de Janeiro, 1981, p. 623.
} 
contrato o fundamento da Sociedade e do Estado origens muito antigas ${ }^{7}$,", assunto este a ser pormenorizados ainda neste paper.

A conduta e o comportamento do homem, de forma antropológica, careciam e ainda há uma imensidão de informações de conhecimentos científicos

O simples fato de produzir algo que lhe favorecia, era o suficiente para se valer nessa condição de reciprocidade.

No grupo tribal em que se concentrava, bem que se observa e se referencia quando o homem participava para o desenvolvimento de sua tribo, pois era um vínculo de uma crença que os membros estáveis possuíam um comportamento voltado ao laço de sangue, observa-se:

Utilizando a ferramenta como um prolongamento e apêndice de seu braço e, ao mesmo tempo, dividindo o trabalhando cooperando com outros homens, a força e a capacidade do homem individual foram multiplicadas e potencializadas no interior do clã, da aldeia ou da tribo ${ }^{8}$.

Pela sua própria necessidade o homem passa a ter um avanço sobre todas as coisas quando este assim, se descobre a possibilidade de produzir algo que venha a satisfazê-lo, para si e para a sua tribo, pois até a essas descobertas, segundo Henrique Garbellini Carnio, "não havia, portanto, uma diferença essencial entre homem, animal, plantas e demais objetos inanimados da naturez $a^{9, ", ~ o ~ h o m e m ~ s e ~ c o m p o r t a v a ~ c o n f o r m e ~ a ~ n a t u r e z a ~ q u e ~ o ~ c e r c a v a, ~ a l e ́ m ~}$ dos mistérios que ela o proporcionava.

Mas nesse comportamento de observar os fenômenos da natureza que estava presente no dia a dia de sua vida recíproca com os demais componentes da sociedade primitiva, o homem "gênero" por sua naturalidade, com uma visão de que tudo possuía um regramento, uma ordem natural:

La ciência comenzo com y uma imagem del mundo em que se descubrieron legalidades em los sucesos del mundo, Ella se inicia com el paso del mito al logos. Y si hay leyes de la naturaleza física? No debe haver tambien de La naturaleza metafísica? No deberán determinarse tambien los costumbres y el derecho mediante la naturaleza ${ }^{10}$.

\footnotetext{
${ }^{7}$ DEL VECCHIO, Giorgio. Direito, Estado e Filosofia. Liv. Ed. Politécnica, Rio de Janeiro, 1952, p. 352.

${ }^{8}$ MELLO, Leonel Itaussu A. e COSTA, Luis César Amad. História Antiga e Medieval. Ed. Scipione, São Paulo, 1993, p. 12.

${ }^{9}$ CARNIO. Henrique Garbellini. Direito e Antropologia: reflexões sobre a origem do Direito a partir de Kelsen e Nietzsche. São Paulo, Saraiva, 2013, p. 32.

${ }^{10}$ KAUFMANN. Arthur. Filosofia Del Derecho. Colombia. Ed. Panamericana. p. 64
} 
O homem passou a observar, pela natureza, que era possível, produzir objetos para o seu conforto e com isso passou a se aprimorar para essa necessidade que o cercava, e constatou que era gratificante, as artes foram aos poucos incorporando no seu ofício, e porque não dizer na sua essência de sobrevivência, adquirindo uma cultura primitiva, "e isso era bom”, assim por dizer de Marconi:

Ele incorpora, através do processo de endoculturação, características próprias do
grupo em que vive, adquirindo uma personalidade básica. Como participante de uma
sociedade e de uma cultura, a pessoa é portadora de caracteres constitucionais
(biopsicológicas) e de experiência sociocultural próprios. Isso lhe confere um tipo de
personalidade que vai determinar ações e reações, pensamentos e sentimentos,
enfim, o seu comportamento na busca de melhor adaptação aos valores
socioculturais do grupo ${ }^{11}$.

Com esse aprendizado, ou melhor, a essa cultura cognitiva adotada trouxe para ele um benefício no seu grupo gentílico na forma da sua natureza, em beneficio a todos.

Sob um novo fenômeno aculturamento, o homem assim, passou a ser um diferencial diante dos objetos inanimados da natureza, das plantas e dos outros animais, diante dessa transposição o objeto passou a ser o referencial, segundo Cretella:

Objetos culturais são aqueles aos quais o homem acrescentou a marca de sua individualidade, objetos que passaram da natureza para a sociedade, numa trajetória do dado ao construído, num trabalho de valoração evidente, numa transposição progressiva da categoria natural para a categoria cultural $^{12,}$

Enfim o homem passou a adquirir, e com isso, aperfeiçoar a arte de produzir objetos, uma descoberta que neste momento passou a possuir um "status" diante de todas as formas que ora a natureza lhe oferecia.

Bem observa o mesmo autor transcreve que "Os objetos naturais são dados ou oferecidos pela natureza", entendo que era por isso que o homem era subordinado, por assim entender, era submisso as leis da própria natureza e de outras formas de vida que cercava o gênero homem como pessoa.

Se para o homem primitivo, o seu comportamento estava adensado conforme as regras de sua comunidade tribal, e que para tanto, os efeitos da reciprocidade, eram

\footnotetext{
${ }^{11}$ MARCONI, Marina de Andrade e PRESOTTO, Zélia Maria Neves. Antropologia: uma introdução. 7 a ed. 5 reimpr. - São Paulo: Atlas, 2013, p. 7.

${ }^{12}$ CRETELLA JUNIOR, José. Curso de Filosofia do Direito; prólogo de Giorgio Del Vecchio. Rio de Janeiro, Forense, 2007, p. 57.
}

\author{
Revista Brasileira de História do Direito | e-ISSN: 2526-009X| Encontro Virtual | v. 7 | n. 1 | \\ p. 21 - 39 | Jan/Jul. 2021.


concernentes de uma habitualidade naquele período, aonde comportamento se delimitava através das suas obrigações.

\section{2) A retribuição, modulações dos usos e dos costumes.}

$\mathrm{O}$ aspecto da retribuição era um fator primordial, pois possuía uma modalidade mais complexa, tendo em vista, que a sociedade primitiva possuía um contorno de complexidade de comportamento interina, uma política de ordem respaldada pelos usos e costumes, inerentes na época.

Nesse primeiro momento, transcende o aspecto do conservacionismo.

Melhor articulando, o comportamento naquela coletividade sobrepujava como uma ordem interna, pois os reflexos dos atos e fatos comprometiam a manutenção do comportamento do gênero homem, bem retrata na escrita, pois o costume na crença dos antepassados era um fator de "dívida cultural", relacionado com as obras se transmitiam entre os personagens em comunhão das gerações, bem descritos nas palavras de Garbellini:

Essa atitude coletivista se manifestava num rígido esquema de conservacionismo. Os vivos eram governados pelo passado e pelos mortos. Estes eram considerados sagrados, e essa crença era tão forte que criou também, sob a base do princípio da retribuição, a tradição de que somente deveria ser feito aquilo que os antepassados faziam $^{13}$.

O conservacionismo foi uma característica essencial, pois o costume era um comportamento intrínseco para a manutenção e com isso sedimentou nos "usos e costumes", muito bem recepcionado nos dias atuais, na legislação brasileira, que de igual, recepciona em partes do comportamento humano na ótica jurídica, nesse sentido:

O Direito Romano admite, em partes sobre o conceito do reiterado comportamento admitido pelo costume, pois bem se manifesta a doutrina de Chamoun:

O costume (mos maiorum, iusnon scriptum) é a repetição constante de certos atos na crença de sua necessidade jurídica. Tinha eficácia análoga à da lei porque, como diziam os romanos, pouco importava que o povo diretamente legislasse nos

\footnotetext{
${ }^{13}$ CARNIO. Henrique Garbellini. Direito e Antropologia: reflexões sobre a origem do Direito a partir de Kelsen e Nietzsche. São Paulo, Saraiva, 2013, p. 49.
} 
comícios ou indiretamente revelasse a sua vontade pela prática reiterada de determinados $\operatorname{atos}^{14}$.

O tema da retribuição vai mais além do que apenas nos "usos e costumes".

Pois, aquela era a base fundamental, a gene mitocondrial, o cerne do relacionamento da atividade e está, é o fator equacionaria dos resultados, ou melhor, a causalidade do comportamento dos antepassados, um obligatio, comportamental, um reflexo dos antepassados em que o homem, assim por entender, se encontrava em débito (debitum).

Assim, esse debitum, não se desfazia ou se diluía durante o tempo, permanecia na obrigação de perpetuar sob as vestes da tradição, ou na melhor dicção "de pai para filho", e assim, sucessivamente.

Mas o que se percebe, que a característica do "conservacionismo" até nesse momento sumariamente questionado, induz, que a componente chave da manutenção da sociedade gentílica, ou tribal.

Tinha o instinto da perpetuação da espécie, pois se descreveu até neste presente, que os antepassados mantinham o mesmo comportamento dos antepassados, uma forma de considerar os atos perfeitos para aquela época.

Com isso, essa perpetuação, recepcionado pelo conhecimento e das práticas usuais, executado pelo comportamento e dos atos possuía um condão validade, em virtude da herança deixada pelos antepassados, Ralph Linton transcreve sobre essa reciprocidade:

A perpetuação da sociedade como entidade funcional é assegurada pela transmissão, de uma geração a outra, do Stock comum de idéias e valores que dão ao grupo sua unidade psicológica e pela recíproca de comportamento, que permite aos membros do grupo viverem e trabalharem juntos ${ }^{15}$.

Prova-se no momento, a princípio, que o homem, por sua natureza, está efetivamente no conceito e por assim dizer, manter às suas crenças pinçadas pelos reflexos comportamentais nos seus antepassados, bem descrito pela perpetuação de sua espécie, nas tarefas pelo fortalecimento e pelas descobertas para o bem em comum.

É uma das características daquela sociedade, pois o homem praticava apenas aquilo que considerava o certo, ou seja, praticava o mesmo comportamento que os demais, bem

\footnotetext{
${ }^{14}$ CHAMOUN, Ebert. Instituições de Direito Romano. São Paulo. Forense, 1950, p. 33.

${ }^{15}$ LINTON, Ralph. O homem: uma introdução à antropologia. Trad. Lavínea Vilela. 12a Ed. São Paulo, Ed. Martins Fontes, 2000, p. 103.
}
Revista Brasileira de História do Direito | e-ISSN: 2526-009X| Encontro Virtual | v. 7 | n. 1 | p. 21 - 39 | Jan/Jul. 2021.


como era estabelecido pelos seus antepassados, pois, como se apensou pelas crenças e os usos e costumes.

Naquele momento nada era estranho, pois se acreditava que o seu comportamento era uma forma natural de se corresponder com os fatores externos.

Ressalta-se que, apesar de que ele vivia em uma comunidade gentílica, vale salientar, que o seu instinto era único e instintivo vingativo, ou em outras palavras, a vingança percorria no seu mais alto sentimento, isto posto era uma qualificadora de seu "status" na comunidade tribal, uma relação entre seus idênticos e voltado a manutenção e perpetuação tribal, " $A$ conduta da vingança é socialmente determinada e expõe com clareza a projeção da justiça sob a forma do princípio da retribuição nas sociedades primitivas ${ }^{16}$.

Ainda quando, na esfera da causalidade, fatores que causassem um resultado extraordinário, anormal as suas capacidades mentais do homem primitivo, despertava a sua atenção, a partir disto, essa causa extraordinária o incorporava na sua vida e no seu comportamento diário, aplicando tal novidade junto a sua comunidade gentílica.

$\mathrm{O}$ homem passou a observar e consequentemente adquiriu uma mentalidade progressiva, pois a essa observação foi possível criar um senso de conhecimento.

Porém, sem desaparecer, ou ficar em desuso o seu comportamento primitivo, mas que os fatos distintos da sua época lhe causaram um despertar para a investigação dos efeitos morais, porém primitiva e retributiva com a sua "gens", essa classificação, advém de uma época pré-romana, conforme retrata o posicionamento de Vogel:

Em realidad, sobre La existência de la "gens" como organización independiente y autônoma no tenemos referencias diretas, ya que solo conocemos a esta institución em la época histórica, es decir, cuando sus funciones primitivas han sido aborbidas por organismos políticos superiores, especialmente por el Estado, o em el caso de Roma, por la "civitas". Por lo cual resulta relativo el conocimiento que podamos tener de lo que la "gens" era en la época pré-romana ${ }^{17}$.

Para o gênero homem, na época era tudo novidade, mas continuava a se comportar pela influência dos laços de sangue com a sociedade em que vivia de forma retributiva, caçava em grupo e vivia em grupo, e não existia o pensamento individual, ou seja, personalista, pois para a sua sobrevivência era necessário pensar em grupo.

\footnotetext{
${ }^{16}$ CARNIO. Henrique Garbellini. Direito e Antropologia: reflexões sobre a origem do Direito a partir de Kelsen e Nietzsche. São Paulo, Saraiva, 2013, p 57.

${ }^{17}$ VOGEL, Carlos Alfredo. História Del Derecho Romano. Buenos Aires. Ed. Perrot. 5a Ed. 1993, p. 68.
}

\author{
Revista Brasileira de História do Direito | e-ISSN: 2526-009X | Encontro Virtual | v. 7 | n. 1 | \\ p. 21 - 39 | Jan/Jul. 2021.


Mas com os fatores extraordinários, o homem passou a observar mais atentamente e buscar respostas para os fatores, que não estava acostumado na sua vida diária, pois ele o interpretava que a sua sobrevivência, além de estar comprometido pela necessidade e sobrevivência em grupo, possuía sim, uma submissão a tudo e a todos de acordo com a sua natureza, assim se traduz a doutrina de Garbellini, "O homem primitivo assumia de tal maneira sua atitude de submissão aos animais, vegetais e até aos utensílios que havia produzido com grande destreza e cuidado que chegava a oferecer-lhes rezas e oferendas ${ }^{18}$ ".

Nesse mesmo sentido, Willis Santiago, transcreve sobre a homogeneidade ou a equiparação do homem primitivo com a natureza e os fatores da causalidade que se transportava para a vida diária, vejamos:

O homem primitivo considerava todas as coisas que despertassem sua atenção como
homogêneas, algo diferente do que ocorre com o homem moderno. Para ele, os
animais, plantas e objetos inanimados eram, em certas situações, identificados como
essencialmente similares aos homens com que convivia em sociedade, ou seja, não
havia uma diferença essencial entre o homem, o animal, as plantas e os demais
objetos inanimados da natureza ${ }^{19}$.

Bem diferente é nos dias atuais, no entanto, os usos e costumes disciplinados pelo comportamento na época primitiva estavam definitivamente caracterizados pela sua essencial sobrevivência, pois somente os fatores que emergissem de forma extraordinária poderiam transpor o homem para uma ciência, o fazer pensar na sua individualidade, que até nesse momento está aquém de acontecer.

Para essa característica, integrante da endoculturação da sociedade embrionária primitiva, merece toda atenção.

A vingança é um mecanismo de defesa e de autodefesa, pois como se sabe, o homem primitivo vivia em grupos, e de costumado chamado de sociedade primitiva

A natureza e a personalidade dessa comunidade são tidas como gentílicas, não pelo fato genérico de gentileza, mas sim, um comprometimento com o seu clã.

Em outras palavras, a vingança, possuía um sentimento moral, pois em virtude da retribuição - como foi diversas vezes comentado - o homem tinha a obrigação de se postar

\footnotetext{
${ }^{18}$ CARNIO. Henrique Garbellini. Direito e Antropologia: reflexões sobre a origem do Direito a partir de Kelsen e Nietzsche. São Paulo, Saraiva, 2013, p.47.

${ }^{19}$ GUERRA FILHO, Willis Santiago. CARNIO, Henrique Garbellini. Teoria Política do Direito: a expansão política do direito. $2^{\text {a }}$ Ed. Ver., atual. e ampl. São Paulo: Ed. Revista dos Tribunais, 2013, p. 29.
}

\author{
Revista Brasileira de História do Direito | e-ISSN: 2526-009X| Encontro Virtual | v. 7 | n. 1 | \\ p. 21 - 39 | Jan/Jul. 2021.


diante de sua comunidade como um operário para a manutenção e a sobrevivência por força dos laços de sangue em que mantinha com os demais.

Talvez a palavra moral, vai mais além que possamos observar.

Trata-se de um comprometimento diante de sua comunidade, uma ordem jurídica, e posto no seio de sua comunidade, um mecanismo de defesa e de penalização, mais usada no interior, pois, o Direito do homem era mais com o seu semelhante da tribo, como um grupo, pois este ainda não absorvia o sentimento do individualismo e sim, apenas em viver em grupo.

Para uma melhor definição, do que seria essa moralidade recíproca, e ainda ser uma conduta primitiva, o comportamento dos indivíduos estava verdadeiramente relacionado a um comportamento de direito que se achavam a forma correta para a manutenção daquela sociedade, muito bem se observa novamente nas escritas de Garbellini:

\footnotetext{
Nesse sentido, por estar a base de sua interpretação homogênea fundada no princípio da retribuição, era evidente que retribuição se exercia não apenas na individualmente, mas sobre todo o grupo, pois o próprio grupo se tornava substância ${ }^{20}$.
}

De toda sorte, o comportamento retributivo, do homem tribal, pode-se notar que existia um comprometimento na sua origem, não apenas pelo modo de viver e na corporação, por assim dizer, uma cooperativa, que além de ser participativo.

Prezava pela moralidade e dos bons costumes que ora era imperativa, mas não era apenas no bom viver em comunhão, a regra jurídica pela reciprocidade diante da blindagem na proteção do seu semelhante, Kelsen, se manifesta nessa linha de pensamento, do estado da homogeneidade entre os indivíduos, e assim, sobrepõe que:

\begin{abstract}
Quando os indivíduos que vivem juntamente em sociedade se conduzem durante certo tempo, em iguais condições, de uma maneira igual, surge em cada indivíduo a vontade de se conduzir da mesma maneira por que os membros da comunidade habitualmente se conduzem...Somente quando estes atos se repetiram durante um certo tempo surge no indivíduo a ideia de se deve conduzir como costumam conduzir-se os membros da comunidade e a vontade de que também os outros membros da comunidade se comportem da mesma maneira ${ }^{21}$. (grifei).
\end{abstract}

\footnotetext{
${ }^{20}$ CARNIO. Henrique Garbellini. Direito e Antropologia: reflexões sobre a origem do Direito a partir de Kelsen e Nietzsche. São Paulo, Saraiva, 2013, p. 48

${ }^{21}$ KELSEN. Hans. Teoria pura do direito. Trad. João Baptista Machado. $8^{a}$ ed.. São Paulo: Editora WMF Martins Fontes, 2009, p. 10
}

\title{
Revista Brasileira de História do Direito | e-ISSN: 2526-009X | Encontro Virtual | v. 7 | n. 1 | p. 21 - 39 | Jan/Jul. 2021.


O aspecto axiológico do direito à igualdade, é considerada como uma prática lícita, além de uma norma legal, e pelo que se observa, mesmo antes do surgimento das escritas, esse direito, foi praticado pelas influências dos costumes, como fonte de um direito outrora já normatizada pelo sistema das práticas empíricas.

E destas normas, sobressai, que uma vez as suas práticas reiteradas, o indivíduo ou o grupo das primevas, se adquire uma perspectiva psicossociológica, em função de uma determinada conduta, uma consciência mnemônica dos atos, dos fatos e os resultados obtidos pelo comportamento.

E destes resultados, que, pacíficos, advém o equilíbrio social, e que tais regras usuais, ou costumeiras, incorporam de forma definitiva, adquirindo um estado de latência do direito fundamental, faz enfim, a gênese de um direito fundamental, do qual se transmitirá para as próximas gerações daquela sociedade.

Observa-se que infringido um conceito, um comportamento, ou em outras palavras a quebra de uma regra, todos estavam sujeitos a uma penalização imposta pelas regras tribais.

Por isso a homogeneização nos princípios da retribuição da sociedade gentílica, insurge assim, mais um fenômeno de comportamento baseado na reciprocidade.

A fidelização dos reflexos e dos resultados, oriundos aos atos comportamentais, do qual recai sobre o benefício da coletividade, o instituto do "medo" passou a ser o aliado abstrato e necessário para a manutenção e o equilíbrio dos bons costumes.

Nota-se que a política da retribuição, atribuída aos povos, possuía um sinônimo com os demais fenômenos culturais, pois um completava politicamente os mecanismos de desenvolvimento da sociedade.

E é nesse sentido que o aspecto retributivo estava corporificado na justiça, no respeito, na crença e no sentimento do medo, inserido como uma forma de penalização pelo desvio das regras impostas pelo desenvolvimento da sociedade tribal, então, mais um mecanismo de retribuição insurge, o da imputação.

Brevemente aludimos Kelsen, na sua obra Teoria Pura do Direito, que traduz de uma visão expansiva, quando relata aos conceitos da causalidade, que "Na descrição de uma ordem normativa da conduta dos homens entre si é aplicado aquele outro princípio 
ordenador, diferente da causalidade, que podemos designar como imputação ${ }^{22, ", ~ e n f i m, ~}$ demonstra-se assim uma forma retributiva, onde estamos diante do fenômeno da imputação, o qual será tratado adiante, quando adentrarmos na penalização e o aparecimento do Direito Penal através da lei de Talião.

É nesse sentimento de vingança, a qual sempre esteve presente nas sociedades gentílicas pelas praticas internas dessas sociedades.

No entanto era a política da penalização ou de imputação, também tinha a sua exteriorização, quando algum membro dessa sociedade sofria uma injustiça por parte das tribos estranhas, ou melhor, externas, aonde o comprometimento fazia com que a todos se vingassem desse mal injusto.

É desse sentimento de vingança, perdura no psiquê do indivíduo nos dias atuais, um estado psicossocial, porém, sendo substituído pela ação do Estado frente a um desequilíbrio dos bons costumes públicos e regras de comportamento humano, sob a ótica legislativa, na proteção e na manutenção da sociedade em geral.

A incursão da atividade vingativa se reflete nas atividades obrigacionais, comportamento este, presente, quando o homem passou a se relacionar com outras tribos.

É na latência do escambo, o percursor das atividades comerciais na era primitiva adentrando para a era medieval, a vingança eclodia no inadimplemento, bem descrito nas palavras de Chamouns:

O conteúdo da obrigação não foi sempre o mesmo. Inicialmente, a obrigação reflete os costumes antigos segundo os quais quem comete um delito submete-se à vingança do ofendido ou de seus parentes que podem prender, matar, ou mutilar o autor do ilícito ${ }^{23}$ ". (grifei).

Sem avançar nos conceitos dogmáticos da questão obrigacional, conforme exposto anteriormente, apenas foi apensado que prova que de fato o homem detinha o sentimento de vingança, uma forma bem natural para aquela época, pratica usual até a edição da Poetélia Papiria, lavrada em 326 A.C.

E quanto ao Direito na obligatio, será feitos apontamentos essenciais neste mesmo paper, a qual dessa atividade empregada incorporada dentro do Direito Romano.

\footnotetext{
${ }^{22}$ KELSEN, Hans. Teoria Pura do Direito. Trad. João Baptista Machado, Ed. Armênio Amado, Coimbra, 1984, p. 119.

${ }^{23}$ CHAMOUNS, Ebert. Instituições de Direito Romano. São Paulo. Forense, 1950, pp. 293-294
}

\author{
Revista Brasileira de História do Direito | e-ISSN: 2526-009X | Encontro Virtual | v. 7 | n. 1 | \\ p. 21 - 39 | Jan/Jul. 2021.
}


Dispostas essas características das sociedades primitivas, percebe-se que sempre esteve presente o mecanismo da retribuição, em todos os momentos participativos de cada homem primitivo.

Dessa retribuição gentílica, o sentimento viver em grupo foi essencial para a perpetuação da espécie "homem".

A sua necessidade de convivência era primordial da sobrevivência, mas que para tanto, as regras inerentes eram contundentes.

Assim, percebe-se que há uma gerência de justiça, que era bem disciplinada, através dos feitos da magia, da crença, do seu conservadorismo e por fim as suas causalidades

Os fatores extraordinários, metafísicos e experimentais, para incitar e provocar a libido da observação, bem como os efeitos da curiosidade e dos expansionismos da memória, uma vez que para o homem primitivo a ciência estava aquém do seu momento, pois os fatos novos para ele era um motivo de reverência da descoberta, e que foram tomando os devidos lugares na vida cotidiana humana.

\section{O comércio "nu", uma relação retributiva, e a aproximação dos povos através das atividades comerciais.}

Uma das modalidades, que merece igual atenção, no sistema retributivo, está concentrado nas atividades comerciais.

Eis que o homem deixou de ser primitivo, passou a se tornar independente, que antes estava subordinado aos fenômenos animal e natural, pois dependia destes para a sua sobrevivência, um breve apontamento neste quesito.

Mas de fato, o homem deixou de permanecer no seu reduto primitivo, e em relação às suas necessidades e as de caráter protetivas, passou a exercer algo incomum, é o de realizar as trocas de mercadorias, costumeiramente conhecido como escambo, a moeda corrente era a própria mercadoria.

Parte-se do princípio que o homem se tornou independente através das trocas comerciais, mais conhecidas como Potlatch?.

A princípio podemos responder que sim; pois foi um grande passo da sociedade primitiva para a civilidade, assim, como nos dias atuais temos os passos dos homens na Lua. 
Mas o Potlatch, fez renascer e fortalecer a aproximação das mais diversas camadas sociais é a transição que mesmo arcaica, mas de um valor inestimável para aquele período em que o homem aceitou a sua condição na relação de consumo e recepcionar as regras e costumes dos estrangeiros, nasce o Direito Internacional.

Nesse sentido, as gêneses das relações comerciais oportunizaram o surgimento do contrato, mas não individual, pois o homem comercializa em grupo para satisfazer as necessidades de sua tribo, assim:

Este sistema de trocas de que o potlatch é a manifestação mais evidente, é a forma arcaica de troca (...) e marca uma fase de transição entre o sistema mais primitivo da prestação total de clã, a clã ou de família a família e o contrato individual, a troca mercantil. Trata-se de formas intermediárias ente a troca por complementariedade, tal como se observa nas tribos australianas, e a economia moderna ${ }^{24}$.

É nesse condão que se abre um importante espaço que ocorre entre o sistema retributivo, aonde o domínio e o poder estão intrinsecamente relacionados entre si.

As relações comerciais, de certa forma, proporcionaram a aproximação das pessoas, mas não com a objetividade de ser estreitar laços de amizades e de ter um convívio familiar, por assim entender, mas exclusivamente na satisfação comercial, pois há um interesse em comum.

O homem não tinha essa afinidade de se relacionar, harmoniosamente, e sabese que inclusive atualmente, a atividade comercial faz a esse princípio, mas com uma exceção, apenas comercial:

\begin{abstract}
Nas economias e nos direitos que precederam os nossos, nunca constatam, por assim dizer, simples trocas de bens, de riquezas e de produtos num mercado estabelecido entre os indivíduos. Em primeiro lugar, não são indivíduos, são coletividades que se obrigam mutuamente, trocam e contratam; as pessoas presentes ao contrato são pessoas morais: clã, tribos, famílias, que se enfrentam e se opõem seja em grupos frente a frente num terreno, seja por intermédio de seus chefes, seja ainda dessas duas maneiras ao mesmo tempo ${ }^{25}$.
\end{abstract}

E porque não afirmar, que esse fenômeno de mercancia, teve um papel importante para a aproximação das famílias, tribos, clãs e atualmente as relações sociais.

\footnotetext{
${ }^{24}$ MAUSS, Marcel, Antropologia, organizador da coletânea Roberto Cardoso de Oliveira: trad. Regina Lúcia Moraes Morel, Denise Maldi Meirelles e Ivone Toscano, São Paulo: Ática, 1979, p. 31.

${ }^{25}$ MAUSS, Marcel. [1872-1950]: Sociologia e antropologia. Trad. Paulo Neves. São Paulo: Cosac Naify, 2003, p.190.
} 
Pactos e acordos internacionais, atualmente, foram e são alvos positivos para uma sociabilidade, entre as nações, indistintamente da raça, no entanto a cultura se faz presente, ressalta-se que deste comportamento teve a sua origem em respeito aos costumes adotados para cada povo que contrai uma obrigação comercial.

Paulo Nader, na sua obra Filosofia do Direito, demonstra uma atividade comercial, mas não era apenas e exclusivo para esse fim, e sim, diante de todas as demais, não havia ainda uma divisão, pois se vale a premissa que o ser humano vivia em bando ou grupo, observa-se:

Primitivamente, o Direito Positivo não possuía divisões em classes ou ramos. Em sua fase pré-cientifica sequer se cogitou sobre a diferenciação entre o Direito Público e Privado, que adveio apenas com o Direito Romano. Os códigos primitivos disciplinavam, indistintamente, todo o tipo de relações sociais, englobando questões de família, trabalho, tributo, comércio, pena ${ }^{26}$.

De fato, como o ser humano na idade das primevas vivia em grupo, a essa regra não se furtou, os direitos sociais e o direito privatista das comunidades, sob o aspecto forte da influência dos costumes.

\footnotetext{
${ }^{26}$ NADER, Paulo. Filosofia do Direito. $21^{\text {a }}$ ed. Rio de Janeiro, Forense, 2012, p. 143
} 


\section{CONCLUSÃO}

É cediço em comentar sobre a conclusão deste artigo, mas é necessário apresentá-lo, pois se trata de uma cultura que se sobressai de inúmeros comportamentos, verdadeiras interpretações para o ramo do Direito.

O Direito é pautado sobre a vertente dos fatos, valores e normas, mas o que se chama a atenção, é que se o fato em si atribui os valores, o comportamento humano sobressai a todos eles, pois é deste comportamento que se busca um equilíbrio voltado para o social, uma segurança jurídica para as regras adotáveis e aceitas por todos.

A gênese jurídica, contemplados pela humanidade, sobressai sobre todos os fatos que o ensejaram; isso se faz prova, que pela sua própria sobrevivência, o homem, teve que se agrupar.

Mas, para o sucesso desse agrupamento, obtiveram o consenso não pelo agrupamento dos indivíduos, e sim, a aceitação e combinações de personalidades, e pelas comutações de ideias; e com essa união de personalidades, mesmo, diferente no sentido biológico, se promove a ação em comum; assim estabelecesse as regras entre esses personagens.

É nesse sentido, que a abordagem exegética da gênese cultural do Direito, induz ao pesquisador demonstrar a necessidade que, compreendendo os fatos pretéritos e os seus acontecimentos, é que se dará uma importância relevante para os fatos nos tempos modernos.

Os aspectos e o expansionismo comercial, foram e é uma das fontes do Direito.

Além dessas atividades comerciais terem proporcionado a aproximação dos povos, foi possível, agregar, valores culturais; uma verdadeira fonte dos fenômenos inseridos no contexto da ciência jurídica, uma transnacionalização dos usos e dos costumes, além das barreiras das soberanias dos povos.

E porque não se afirmar, a contemplação dos fatos futuros; o Direito é a grande ferramenta que equaliza e determina as regras, e lança as criticas construtivas para a manutenção da segurança jurídica, pelos fenômenos mutacionais e comportamentais. 


\section{Bibliografias}

ALVES. José Carlos Moreira. Direito Romano. Ed. Borsai. Rio de Janeiro. 1966.

ARANGIO-RUIZ, Vincenzo. Instituciones de Derecho Romano. Trad. José M. Caranés Ferbo. Ed. De Palma. Buenos Aires. 1973.

BATALHA. Wilson de Souza Campos. Introdução ao Estudo do Direito. Forense. 1981.

CAMPOS, Carlos. Sociologia e Filosofia do Direito. Belo Horizonte, Ed. Cardal, $2^{\text {a }}$ Ed. Belo Horizonte, 1961.

DEL VECCHIO, Giorgio. Lições de Filosofia do Direito. Trad. Antonio Jose Brandão. $4^{\mathrm{a}}$ Ed. Ed. Armébio Amado, Coimbra, 1972.

CARNIO. Henrique Garbellini. Direito e Antropologia: reflexões sobre a origem do Direito a partir de Kelsen e Nietzsche. São Paulo, Saraiva, 2013.

CRETELla JUNIOR, José. Curso de Filosofia do Direito; prólogo de Giorgio Del Vecchio. Rio de Janeiro, Forense, 2007.

FRANCISCI, Pietro di. Sintesis Histórica Del Derecho. Trad. Urcinio Alvarez. Ed. Revista de Derecho Privado. Madrid. 1954.

GUERRA FILHO, Willis Santiago e CARNIO, Henrique Garbellini. Teoria Política do Direito: a Expansão Política do Direito. $2^{\mathrm{a}}$ Ed. Rev. Ampl. São Paulo, Ed. Revista dos Tribunais. 2013.

KELSEN. Hans. Teoria pura do direito. Trad. João Baptista Machado. $8^{\mathrm{a}}$ ed.. São Paulo: Editora WMF Martins Fontes, 2009.

Coimbra, 1984.

Teoria Pura do Direito. Trad. João Baptista Machado, Ed. Armênio Amado,

MARCONI, Marina de Andrade e Presotto, Zélia Maria Neves. Antropologia: uma introdução. 7 ed. - 5 reimpr. - São Paulo: Atlas, 2013.

MAUSS, Marcel. [1872-1950]: Sociologia e antropologia. Trad. Paulo Neves. São Paulo: Cosac Naify, 2003.

Antropologia, organizador da coletânea Roberto Cardoso de Oliveira: trad. Regina Lúcia Moraes Morel, Denise Maldi Meirelles e Ivone Toscano, São Paulo: Ática, 1979.

MELlO, Leonel Itaussu A. e COSTA, Luis César Amad. História Antiga e Medieval. Ed. Scipione, São Paulo, 1993.

MULLER. Friedrich. O Novo Paradigma do Direito: Introdução à Teoria e Metódica Estruturantes. São Paulo. Ed. Revista dos Tribunais, 2007. 
NADER, Paulo. Filosofia do Direito. 21ª ed. Rio de Janeiro, Forense, 2012.

ROULAND, Norbert. Nos confins do Direito. Tradução de Maria Ermantina de Almeida Prado. São Paulo: Martins Fontes, 2003.

TELLES JUNIOR, Goffredo. A Criação do Direito, $3^{\text {a }}$ ed. São Paulo: Saraiva, 2014. 